\title{
A RELAÇÃO ENTRE NORMA E VALOR EM NICOLAI HARTMANN
}

\section{Ricardo Tavares da Silva}

Universidade de Lisboa

\section{Introdução}

\subsection{Alguns dados biográficos}

Nicolai Hartmann nasceu em 1882 em Riga, na Letónia, então pertencente ao Império Russo, e morreu em 1950 em Gottingen. De ascendência alemã, integrava a vasta comunidade alemã presente, à altura, nos países bálticos, tendo toda a sua carreira académica sido feita na Alemanha, pelo que estamos, sem dúvida, perante um filósofo da cultura alemã.

Entre outras posições de regência, ocupou a cadeira de filosofia na Universidade de Berlim. Cumpriu serviço militar durante a primeira guerra mundial, período durante o qual esboçou muitas ideias que viriam ser integradas no seu grande tratado de filosofia moral, Ética.

\subsection{Aobra Ética (Ethik)}

Após 10 anos de esforços de investigação, publica Hartmann, em 1926, a sua obra Ética, tida pelo autor como uma continuação crítica de $O$ Formalismo na Ética e a Ética Material dos Valores de Max Scheler. O conceito central presente em ambas as obras é o de valor: todo o fenómeno ético é entendido em torno desse conceito-chave.

Tal como Scheler, Hartmann parte de pressupostos fenomenológicos e aplica-os à análise da vida afetiva, passando esta a ser interpretada como vivência de valores. Porém, Hartmann afasta-se de Scheler em muitos pontos, pois defenderá, entre outras coisas, a absoluta objetividade dos valores. 
Hartmann visa fornecer um enquadramento teórico que afaste a ética daqueles que, no seu entender, são os seus três principais inimigos: o idealismo (ou subjetivismo), o empirismo e o relativismo. Assim, defende o autor que os valores, que constituem o fundamento de todo o fenómeno ético, são reais (ou objetivos), são cognoscíveis a priori e são absolutos. Estas três propriedades estarão intimamente interligadas.

\subsection{O problema em análise}

Na primeira parte da sua Etica, ${ }^{1}$ Nicolai Hartmann aborda, entre outros, o problema da relação existente entre valor e norma. Hartmann aceita, aí, o princípio basilar avançado por Scheler, segundo o qual todo o dever-ser (toda a norma) é fundado(a) num valor. É este princípio determinante da relação entre valor e norma que constitui o traço distintivo essencial entre a abordagem teórico-normativa da corrente conhecida por Filosofia dos Valores e a abordagem teórico-normativa kantiana e neokantiana.

A intuição imediata subjacente a este entendimento é a seguinte: qualquer norma que possamos conceber fará algum tipo de referência a um valor; por exemplo, a norma (concebível) pela qual o homicídio é proibido de alguma maneira remete para o valor da vida humana. Porém, autores como Scheler e Hartmann vão mais longe e defendem, mesmo, que são os valores que conferem fundamento ou inteligibilidade às normas: qualquer norma remete para um valor porquanto este lhe confere sentido, encontrando-se neste o "porquê" daquela. Assim, o homicídio será proibido (se o for) porque a vida humana constitui (se constituir) algo de valioso.

A normatividade não se encontra, deste modo, privada de materialidade ou conteúdo: a ética dos valores é uma ética material, por contraposição ao formalismo presente na ética kantiana. Para Scheler e Hartmann, princípios e normas destituídos de conteúdo não são, verdadeiramente, princípios nem normas, pois que nada determinam. Os valores garantem esta materialidade enquanto, na mesma medida, constituem, também, a razão de ser dessa mesma normatividade. E, neste aspecto, os valores possuem a função metafísica (por assim dizer) de evitar a existência de normas sem sentido.

Esta tese, a da estreita dependência das normas face aos valores, tem de ser, então, justificada: há que mostrar ou demonstrar que uma tal íntima relação existe. O caminho parece começar na natureza dos próprios valores: será da análise do conceito de valor que se descobrirá o seu fundar o dever-ser.

1 Hartmann, Nicolai, Ethics. Moral Phenomena, trad. Andreas Kinneging, 3. a edição. New Jersey: Transaction Publishers, 2007. 
Porém, há que determinar se essa natureza é bastante para fundar a normatividade ou se, pelo contrário, algo mais há que acrescentar à mesma. Contra Scheler, Hartmann defende, como se verá, a primeira hipótese.

É de notar, pelo que se disse, que o nível da especulação teórica a que nos encontramos não é o de saber o que é ou não é normativamente exigido, nem o que é bom ou mau ou o que é certo ou errado. Encontramo-nos ao nivel do fundamento das normas, pelo que o que se procura é o seu "porquê" (porque é normativamente exigido o que é normativamente exigido). Pode dizer-se que, aqui, é que nos encontramos verdadeiramente ao nível da filosofia normativa (e não da ciência normativa).

Daí que, em rigor, nem se tenha de aceitar que existem, mesmo, normas e valores. Basta pensar em termos hipotéticos ou condicionais e não categoricamente: se falarmos em normas, então temos de falar em valores, como seu fundamento - estes aparecem como condição de possibilidade (para usar terminologia kantiana) daquelas. À partida, é possível negar que existam mesmo normas e valores e aceitar que exista, entre ambos os conceitos, o nexo atrás referido.

\section{Nicolai Hartmann: do valor à norma}

\subsection{Dever-ser ideal}

a) Os valores como essências

A justificação dada por Hartmann assenta na natureza dos próprios valores. E, antes de mais, os valores são, para Hartmann, o mesmo que as Ideias são para Platão: essências ou objetos meramente abstratos, que subsistem num mundo próprio (o inteligível ou ideal) e não pertencem à realidade espácio-temporal. Integram a estrutura desse plano ideal, tal como qualquer objeto ideal (como os objetos matemáticos), enquanto conteúdos (puros) susceptiveis de ser exemplificados por objetos reais (os bens, objetos detentores de valor).

Assim, os valores, não obstante não serem espácio-temporalmente reais, possuem a sua própria existência objetiva. Hartmann é peremptório quanto a este aspecto: a idealidade dos valores não é uma idealidade subjetiva - eles subsistem independentemente de sujeitos cognitivos e agentes. Comportam-se, deste modo, como os universais se comportam para um realista dos universais.

Para Hartmann, a esta idealidade objetiva dos valores corresponde uma apreensão cognitiva puramente a priori dos mesmos, sob a forma de uma intuição emocional. Desta maneira, torna-se possível um a priori material, 
não implicando o carácter a priori do conhecimento o seu carácter formal, como entendera Kant. Aqui, sobressai outra particularidade da Filosofia dos Valores: os valores são captados afetivamente; são sentidos, não conhecidos (em sentido estrito) nem pensados.

\section{b) Os valores como princípios}

Tal como a esfera do real, também a esfera do ideal tem as suas determinações, isto é, as suas leis e os seus princípios: Princípios da esfera ideal são, por exemplo, os princípios lógicos e matemáticos, assim como as categorias ou conceitos fundamentais. Ora, para Hartmann, os valores também são princípios: são determinações da esfera ideal, pelo que estamos perante uma categoria especial de princípios, os princípios éticos ou axiológicos.

Porque os valores são objetos meramente ideais ou abstratos (desligados, por natureza, do espaço e do tempo), os mesmos são, enquanto princípios, princípios da esfera ideal. Quanto à sua origem ou natureza, os princípios éticos ou axiológicos são ideais. Porém, quanto ao seu objeto, não se ficam pela sua mera idealidade, pois que visam determinar a realidade espaciotemporal. E, neste sentido, são princípios da esfera real.

Como afirma Hartmann, a natureza dos valores não se evapora na essencialidade: eles transcendem essa subsistência ideal, pois que (in)tendem para a realidade. Se assim não fosse, careceria de significado falar em princípios éticos ou axiológicos. Assim, embora de um modo especial, eles também são determinações da esfera real: são susceptíveis de atuar sobre a realidade espácio-temporal, acrescentando algo à natural constituição desta última.

Em última instância, os valores acabam por modificar a própria realidade espácio-temporal, como se de um poder ou uma força causal se tratasse. Porém, não o farão incondicionalmente, como o fazem as leis da natureza: a sua eficácia no mundo espácio-temporal depende da mediação de agentes. A agência e, antes, a consciência valoradora, constituem, assim, uma condição necessária da intervenção dos valores na realidade.

Hartmann distingue, por isso, dois momentos de atualidade ou positividade dos princípios axiológicos.

Antes de mais, os valores são princípios da esfera ética atual, como diz o próprio. Aqui, os valores surgem como determinações dirigidas a uma consciência de um sujeito, com vista a serem prosseguidos pela vontade desse sujeito. Segundo o autor, o fenómeno da consciência moral constitui uma clara evidência da atualidade dos valores.

Porém, enquanto que, na esfera ideal, os valores são determinações invioláveis, supremas, para as quais não há resistência (tal como acontece com os princípios ontológicos), na qualidade de princípios da esfera atual, eles já 
não o são. Este duplo carácter dos princípios axiológicos - inviolabilidade na esfera ideal e violabilidade na esfera real - torna-se manifesto num único fenómeno: o da sua negação pela vontade livre. Ao resistir às determinações axiológicas, o sujeito não deixa de se encontrar por elas pressionado; mas, ao negar-se a segui-las, está a resistir às mesmas.

Se o sujeito relativamente ao qual os princípios axiológicos de dirigem se determinar pelos mesmos, então eles passam a ser, também, agora, princípios da esfera ética real. Pela agência do sujeito, os princípios éticos ou axiológicos passam a pertencer ao conjunto das determinações do mundo espácio-temporal. Como refere Hartmann, se as ações do sujeito estivessem sob o controlo dos valores como estão sob o das leis das categorias (leis ontológicas), então a sua determinação não se distinguiria da dos processos naturais.

\section{c) O dever-ser contido na natureza dos valores}

Dito isto, chegamos ao cerne da questão em análise: de que modo se relacionam valor e norma para Hartmann?

Como afirma o autor, nas características dos valores como princípios da esfera ideal encontra-se contido o conceito de dever-ser. Como aos valores pertence a tendência para a realidade, apesar da sua idealidade, também a eles pertence essa tensão, face à realidade, para ser. Os valores visam transcender a esfera ideal a que pertencem de modo a realizarem-se espácio-temporalmente. Nisto consiste o dever-ser, o momento normativo dos valores.

Portanto, aos valores, como princípios da esfera ideal, é necessariamente inerente o dever-ser, também ele um dever-ser meramente ideal. Este é o dever-ser que determina indiretamente a realidade espácio-temporal, segundo uma necessidade que não é ontológica. Como diz Hartmann, as modalidades ontológicas são inadequadas para expressar a natureza da normatividade, nomeadamente, desta normatividade situada num plano puramente ideal.

O autor tem o cuidado de advertir que valor e norma não são, em rigor, idênticos. Dever-ser significa direção para algo; valor significa esse algo para o qual essa direção aponta. O que existe, sim, é uma bi-condicionalidade: 0 alvo condiciona a direção e a direção para esse alvo condiciona o modo de ser deste último. Noutra perspectiva, dir-se-á que este duplo ou recíproco condicionamento resulta do facto de o dever-ser constituir a estrutura e a modalidade do valor, enquanto que o valor constitui o conteúdo do dever-ser.

Este dever-ser ideal, embora projetado para a realidade, é indiferente a como esta seja. Ou seja: embora vise determinar um certo estado de coisas, a sua determinação não depende de esse estado de coisas ser ou não o caso. $O$ dever-ser ideal existe quer a realidade seja quer não seja como deve ser. Pegando num exemplo apresentado pelo autor, tem sentido dizer que deve 
haver paz universal entre as nações mesmo quando esta já exista, pois que isso equivale a dizer, simplesmente, que a paz universal entre as nações é algo valioso.

A este entendimento opõe-se o de Max Scheler, que, não obstante fundar o dever-ser no valor, considera que na natureza dos valores não se encontra contido qualquer momento normativo. Isto, porque os valores, nas suas palavras, são indiferentes a existirem ou não existirem, enquanto que o dever-ser não o é. Perante o possível existir e não existir, surge uma relação do valor com essa possibilidade, sob a forma de dever-ser, relação, essa, que não se confunde com o próprio valor.

O principal argumento de Scheler consiste numa redução ao absurdo. $O$ dever-ser exige que se realize um valor enquanto este não se encontrar realizado, pelo que, já se encontrando realizado, não há dever-ser. Portanto, quando os valores se encontram realizados, deixa de haver a exigência de os mesmos se realizarem. Se o dever-ser fosse inerente ao valor, das duas, uma: ou não seria possivel a sua realização; ou o valor, ao ser realizado, deixaria de ser valor, pois que despareceria o dever-ser. Ora, qualquer uma destas hipóteses é implausível (sendo a última, mesmo, absurda). Consequentemente, aos valores não pode ser inerente o dever-ser.

Johannes Hessen reforça este entendimento com a consideração de que há valores que, por natureza, já se encontram realizados, como é o caso do valor do sagrado. Se existe uma divindade, cuja existência terá de ser necessária, e se esta possui um valor que lhe é característico, então estamos perante um valor-realidade, como Hesssen the chama. Ora, encontrando-se já realizado, não há qualquer exigência de realização desse valor. Porém, não deixa de existir um valor. Como tal, ao valor não é inerente o dever-ser.

Hessen avança, ainda, com outro argumento, desta feita, de carácter fenomenológico. É possível apreciar qualquer qualidade valiosa das coisas meramente em abstrato, na sua idealidade, independentemente de sabermos se tal qualidade valiosa deve ou não existir. Pensemos na justiça: podemos simplesmente captar a sua validade (contemplá-la) sem com isso nos sentirmos vinculados a uma exigência ou a um apelo dirigido por esse valor. Os valores apresentam-se em nós, antes de mais, destituídos de carga normativa.

\subsection{Dever-ser positivo}

Hartmann defender-se-á operando a distinção entre dever-ser ideal e dever-ser positivo. O dever-ser ideal não é, ainda, um dever-ser dirigido concretamente à realidade espácio-temporal, visando determiná-la. Esse papel pertence ao dever-ser positivo ou atual, que surge quando a esfera do real e a esfera do ideal se encontram em oposição ou tensão. 
Aos valores é inerente o dever-ser ideal, não o dever-ser positivo. Com a realização de valores, desaparece o dever-ser positivo, pois que desaparece a oposição entre as esferas real e ideal. Porém, não desaparece o dever-ser ideal, assim como não deixa, por isso, o valor de ser valor por se encontrar realizado. Como diz o autor, algo que deva ser continua a dever ser (idealmente) mesmo que já o seja.

Assim, são duas as condições necessárias para que haja o dever-ser positivo ou atual: que haja o dever-ser ideal; que a realidade espácio-temporal não esteja conforme com esse dever-ser ideal. Basta que uma destas condições não se verifique para que deixe de haver dever-ser positivo; e basta que ambas se verifiquem para que haja dever-ser positivo.

Contrariamente ao dever-ideal, este dever-ser positivo ou actual não é, então, indiferente a como seja a realidade. É por a realidade não ser como deve ser que existe o dever-ser positivo, enquanto irradiação concreta do dever-ser ideal. O converso já não é verdadeiro, visto que a realidade espácio-temporal não depende do dever-ser positivo: o mundo ontológico manter-se-ia tal como é mesmo que não existisse qualquer dever-ser.

Para Hartmann, o mundo é feito de "camadas", sendo umas sobrevenientes face a outras (apoiam-se nestas). As "camadas" superiores são mais fracas no sentido de dependerem das "camadas" de base mas são qualitativamente mais fortes. Ora, a "camada" dos valores é a mais elevada de todas; daí que, não obstante depender de todas as outras para existir, a elas se impõe qualitativamente sob a forma do dever-ser.

Em suma, o dever-ser positivo constitui a concretização da tendência dos valores como princípios para se realizarem espácio-temporalmente. Os valores, na sua idealidade, apenas são; só na sua referência à realidade (nesta sua direcionalidade) constituem um dever-ser (ideal). O dever-ser, portanto, consiste na atualização dessa mesma referencialidade ou da tendência para a realização.

\subsection{Dever-fazer}

Porém, o dever-ser positivo ainda não constitui um dever-fazer. O dever-ser positivo encontra-se a meio-caminho entre o dever-ser ideal e o deverfazer. O dever-fazer é o dever-ser positivo dirigido a um agente (sujeito ativo, nas palavras de Hartmann). Supõe, portanto, a existência de algo que possa agir, que possua vontade. Na medida em que é determinado por este deverfazer, o sujeito ativo determina a própria realidade espácio-temporal, sob a forma de condutas, atitudes mentais ou tendências.

Como havia sido dito aquando da análise dos valores como princípios da esfera real, estes só determinam a realidade indireta e condicionalmente, mediante a intervenção de um agente. É este que vai proceder à realização dos 
valores, a sua transição da esfera ideal para a esfera real. Ora, o que vai determinar normativa mas diretamente o próprio agente é o dever-fazer: é este que vai refletir a oposição das esferas e o dever-ser positivo daí resultante (em conjunto com a tendência dos valores para a sua realização) num sujeito (que é, primeiro, um mero sujeito cognitivo/avaliativo e, só depois e principalmente, um sujeito volitivo/ativo).

Porém, este sujeito possui as suas próprias determinações reais, independentemente da determinação do dever-fazer; ele próprio faz parte da realidade espácio-temporal. Não há, assim, garantia de que os valores efetivamente se realizem: não há garantia de que o sujeito se sinta atraído para os valores (embora este atraiam) nem que execute as determinações normativas (embora estas existam). Isto é o que Hartmann designa de fraqueza dos princípios axiológicos.

Claro que a contrapartida desta fraqueza é a força do sujeito, a sua posição de poder face à realidade. Por um lado, enquanto sujeito activo, pode moldar e transformar a realidade; pode acrescentar valor a esta, ser um pequeno criador. Por outro lado, este sujeito ativo é livre de agir, no sentido de poder não fazer o que sente que deve fazer (Hartmann nega, portanto, o internalismo, quer moral, quer motivacional).

Assim, o agente encontra-se comprimido entre duas ordens de determinações, gerindo esse confronto e desequilibrando-o, ora para um lado, ora para outro. Como tal, ele encontra-se continuamente confrontado com escolhas, decisões, sendo responsabilizado pelas mesmas. Enquanto mediador entre a esfera ideal dos valores e a esfera real da existência, o agente tem a seu cargo a administração da interação entre as mesmas.

Pelo que foi dito, pareceria que os valores, que não necessitam de permissão do sujeito para existirem por si ou autonomamente, já careceriam da mesma para se imporem na realidade espácio-temporal. Mas não. Os valores podem encontrar-se realizados sem a mediação de um sujeito; pode tal acontecer acidentalmente, pela cega necessidade ontológica. Acontece que, a ser assim, não se encontram realizados na qualidade de princípios da esfera ideal, de dever-ser. Só a realização mediada por um sujeito ativo confere esse estatuto especial à realização de valores. Portanto, são o agente e, como tal, o deverfazer os garantes de uma realização de valores qua realização de valores devida.

Esta distinção entre realização formal e mera realização material de valores constitui o equivalente, na teoria de Hartmann, da distinção kantiana entre moralidade e mera legalidade. Uma ação (generalizando, um estado de coisas) só vale mesmo como cumprimento de uma exigência normativa se passar pela intervenção de uma subjetividade cognitivo-volitiva. Nos nossos dias, tal questão cabe no debate relativo à distinção entre uma teoria do bem e uma teoria do certo. 
São estas as razões que levam Scheler a considerar que só o dever-ser dirigido a um sujeito consiste num verdadeiro dever-ser normativo. $O$ dever-ser desligado de uma consciência que o assimile e de uma vontade que o cumpra constitui um mero dever-ser ideal, não possuindo, ainda, normatividade. Só uma exigência dirigida ou concretizada constitui uma norma.

\section{Apreciação crítica}

\subsection{Da norma ao valor}

Como se viu, para Hartmann, é do valor que se infere a norma, por esta se encontrar conceptualmente contida naquele. Dada a definição de valor, daquilo que o caracteriza, chega-se ao conceito de norma, pelo que aquele implica analiticamente esta última. O sentido da relação existente entre ambos é, então, também, do valor para a norma (para além desta para aquele).

Ora, como Hartmann defende que, apesar desta bicondicionalidade conceptual existente entre valor e norma, não há identidade entre ambos (a relação não é reflexiva), há que explicar como é isso possível: como pode um implicar conceptualmente o outro sem que se identifiquem? Dito de outra maneira, tem Hartmann de demonstrar que o dever-ser ideal (porque é este que está em questão) é distinto do puro valor não obstante cada um desses conceitos se encontrar contido na definição do outro.

Quanto a este aspecto, a objeção de Hessen parece ser decisiva: é perfeitamente possível pensar num qualquer valor sem pensar em normas a ele associadas, embora já não seja possível pensar em normas sem pensar em valores. A apreciação de uma qualidade valiosa não nos força a aceitar uma exigência de a respeitar: podemos contemplá-la em abstrato sem sentirmos qualquer tipo de dever-ser perante ela. Aliás, é isso mesmo que significa pensar num valor em abstrato: trata-se de pensá-lo desligado de qualquer normatividade.

Algo é acrescentado ao valor para que haja norma; esse não é suficiente, embora seja necessário. Os valores, para se "normatizarem", têm de se concretizar ou realizar: têm de ser exemplificados ou instanciados (em bens ou valentes) e existir espácio-temporalmente. Nenhum valor que permaneça na sua idealidade possui força normativa. Neste aspecto, Scheler tem razão: no momento normativo, alguma relação existe entre o valor e a realidade.

Porém, Hartmann refere traços intrínsecos ao conceito de valor que préanunciam esse momento normativo. Isto, porque no significado de "valer" aparece contido aquilo a que se pode chamar de "merecimento" de respeito: os valores apelam para serem respeitados. Há como que uma luminosidade que lhes é inerente e exclusiva, um chamamento no sentido de ser adoptada uma especial atitude perante os mesmos. 
Facilmente se percebe porque é esta luminosidade ou esse merecimento de respeito intrínseco aos próprios valores: trata-se da própria validade dos mesmos que se encontra presente, do particular modo de ser do valer. Nesta perspectiva, não há como não ir ao encontro de Hartmann. Mas esta validade não significa normatividade: não há, ainda, exigência, quer quanto a como deva a realidade ser, quer uma exigência especialmente apontada ou dirigida a uma situação particular. Um valor, fechado em si mesmo, nada exige.

Pensemos, por exemplo, no valor da dignidade humana. Este, na sua "existência" abstrata, nada exige: não tem sentido falar no dever de respeitar a dignidade humana em abstato; somente quanto a portadores de dignidade humana tem sentido dizer que deve haver respeito, contando que os mesmos existam espácio-temporalmente. Porém, a norma que exige respeito concreto por entes dotados de dignidade humana pressupõe um "apelo" já contido no próprio valor da dignidade humana, que constitui a sua validade inerente.

Assim, Hartmann peca, na sua análise da relação entre valor e norma, por não distinguir perfeitamente validade de normatividade, entendida aquela como o particular modo de ser dos valores e esta como a exigência dela resultante. Muito do que este autor diz relativamente ao dever-ser ideal serve perfeitamente para falar do valer intrínseco aos valores mas já não para falar da norma.

Consequentemente, a única inferência a operar será no sentido da norma para o valor: o conceito de norma de alguma maneira remete ou devolve para o conceito de valor - no significado de norma encontra-se contido o significado próprio de valer. $O$ converso já não é verdadeiro.

\subsection{A distinção entre norma e conteúdo da norma}

Como foi dito, a norma constitui algo mais relativamente ao valor. Autores como Scheler e Hessen consideram que esse algo mais se encontra numa relação com a realidade. Entendem os mesmos que essa relação se funda na tendência dos valores para se realizarem espácio-temporalmente: os valores devem existir. Como se viu, afirma Hartmann que o valor é o alvo para o qual se dirige o dever-ser, sendo, nessa qualidade, o fundamento deste. Portanto, a formulação geral das normas será algo como "Deve existir valor".

Acontece que perguntar o que a norma tem estruturalmente a mais face ao valor não é o mesmo que perguntar o que exige a norma. No primeiro caso, é a relação entre valor e norma que se encontra em questão, clarificando-se o modo como aquele fundamenta esta última. No segundo caso, é o conteúdo da norma que se encontra em questão, como deve a realidade ser. Pode dizer-se que a primeira questão prende-se com a forma da norma e a segunda com a sua matéria. Embora interligadas, as duas questões não se confundem. 
Como resposta à primeira questão, deve dizer-se que a norma constitui uma relação entre o valor e a realidade atual ou efetiva. $O$ valor aparece, aqui, como relatum da relação normativa. E essa relação consiste, então, antes de mais, numa realização do valor: há um bem ou valente que exemplifica ou instancia uma qualidade axiológica e que existe espácio-temporalmente. Por outro lado, essa existência é, como se disse, atual ou efetiva: já há um valor realizado, não um estado de coisas possível ou potencial.

A normatividade explica-se, assim, com base na existência espácio-temporal dos valores: estes deixam de estar fechados em si mesmos e projetam-se no espaço e no tempo; através dos bens ou valentes a quem atribuem a sua validade, abrem-se ao mundo e, deste modo, comunicam essa mesma validade. Recorrendo-se a uma expressão vulgar mas perfeitamente adequada a este contexto, dir-se-á que, ao existirem, os valores (mais especificamente, os valentes) "dão-se ao respeito" (estão aí para serem respeitados).

Nesta perspectiva, os mediadores dos valores na realidade são as coisas ou os objetos que os incorporam, ou seja, os bens ou valentes. São realizadores de valores no sentido que, ao exemplificá-los ou instanciá-los, fazem com estes existam realmente. Porém, não o fazem por um ato de vontade, por uma determinação sua (até porque podem ser destituídos de vontade).

Recuperando o exemplo atrás apresentado, o valor da dignidade humana converte-se numa norma através da existência espácio-temporal dos portadores individuais de dignidade humana, pois que, assim, a validade inerente a esse valor é projetada para fora dele mesmo, indo ao encontro de outros existentes. Assim, o merecimento de respeito pela dignidade humana é "espalhado" espácio-temporalmente, o que equivale a dizer que surge a norma "Fulano tal deve ser respeitado na sua dignidade".

Disto não se segue que o conteúdo das normas seja o de realizar valores. Pelo contrário: como a norma se identifica com o valor realizado no espaço e no tempo, essa realização constitui um pressuposto para que se exija o que se exige. As normas exigem, sim, que se respeite valores (mais concretamente, os seus portadores, os bens ou valentes). Esta resposta à segunda das questões apresentadas resulta diretamente da análise feita à primeira dessas questões.

$O$ respeito por valores constitui algo diverso da realização de valores. Desde logo, por não implicar, por si só, qualquer tipo de efeito produtivo: pode constituir um mero comportamento, uma simples ação ou omissão. Depois, mesmo sendo concebível a exigência de realização ou produção, a mesma constitui, em rigor, uma exigência de respeito pela existência de algo, aparecendo esta existência como o portador de valor no qual se funda aquela exigência normativa.

Pense-se na norma geral "Não se deve matar". A norma propriamente dita encontra-se na parte "não se deve" (uma proibição) e o conteúdo da mesma 
encontra-se no estado de coisas (não-normativo) "matar". Se restringirmos o este conteúdo à morte de humanos, exige-se, aí, que não se provoque a inexistência de humanos (particulares). Isto equivale a dizer que deve ser respeitada a existência de humanos (o que é diferente de dizer que devem ser respeitados humanos, embora possa haver algum nexo entre ambos os conteúdos), constituindo o respeito pela existência, consequentemente, o conteúdo da exigência normativa em questão.

Ao nível do conteúdo da norma, o valor ou valente aparece como relatum de uma relação eventual, a relação de respeito pelo valor/valente, que é tida como a que deve efectivar-se. Portanto, qualquer proposição normativa tem por conteúdo outra proposição (à partida, não normativa). Assim, a norma obriga (ou proíbe) que um determinado estado de coisas se concretize num fato, independentemente de já o estar ou não. Ao "dever" caraterizador da norma surge contraposto o "ser" do estado de coisas presente no seu conteúdo - o "dever-ser" consiste na unidade de norma e conteúdo normativo. $O$ valor surge, aqui, como parte do conteúdo da norma, não como parte da própria norma.

Em suma. Há uma dupla relação entre valor e norma: uma, quanto à forma, por assim dizer, e outra, quanto à matéria. A esta dupla relação entre valor e norma corresponde a distinção entre norma e conteúdo da norma. Só quanto à primeira dessas relações tem sentido invocar-se a noção de realização de valores. O conteúdo da norma, esse, não tem de consistir numa realização de valores, contrariamente ao defendido por Hartmann.

\subsection{A distinção entre norma e aplicação da norma}

Do fato de a norma se distinguir da validade intrínseca dos valores não se segue que a distinção avançada por Hartmann entre dever-ser ideal e dever-ser positivo ou atual não seja de acolher. Neste aspeto, há que defender Hartmann das críticas de Scheler: algumas das observações daquele relativamente à normatividade do dever-ser ideal têm pertinência.

As normas existem mesmo quando não se verifica alguma situação relevante para a sua aplicação. Pensemos no exemplo avançado por Hartmann, o da paz universal entre as nações. Imagine-se que não estão reunidas as condições para que exista paz universal entre as nações; que é impossível, no imediato, que a mesma se dê. Deste facto não se segue a inexistência de uma norma que determine que exista um tal estado de coisas: caso essa existência seja valiosa, tem todo o sentido dizer que, independentemente das circunstâncias, deve existir paz universal entre as nações.

A configuração da realidade não condiciona a existência das normas aptas a regulá-la nem o seu conteúdo. Assim deve ser interpretada a chamada 
lei de Hume (pelo menos, numa versão de pendor menos epistémico e mais metafísico). Neste sentido, tal como os valores, as normas são totalmente indiferentes a como a realidade seja. A normatividade só se encontra dependente da projeção da validade dos valores no espaço e no tempo, não do seu efetivo reflexo na realidade. Consiste, portanto numa quase-relação do existente valioso com outros existentes.

Agora, imagine-se que estão reunidas as condições para que exista paz universal entre as nações; que é possível, no imediato, que a mesma se dê. Para além da exigência em abstrato de existir um tal estado de coisas, acresce um concreto direcionamento dessa exigência: a norma dirige-se a uma situação concreta, com intervenientes concretos, pelo que surge o dever concreto de fazer com que exista paz universal entre as nações. A aplicação da norma à realidade que (in)tende a regular, essa, sim, depende de como esta seja.

A distinção que Hartmann opera entre dever-ser ideal e dever-ser positivo ou atual corresponde à distinção, porventura tecnicamente mais rigorosa, entre norma (ou a sua existência, aquilo que se designa de validade normativa) e aplicação da norma (ou a sua vigência, aquilo que se designa de eficácia normativa). O dever-ser ideal, a norma, tende a regular a realidade; mas só o faz efetivamente quando se verificam certas condições (previsão, causa ou antecedente normativo), surgindo, como resultado, o dever-ser atual, a aplicação da norma (estatuição, efeito ou consequente normativo).

O dever-fazer corresponde, claro, a um caso particular de aplicação da norma, a aplicação a sujeitos, na qualidade de potenciais agentes. A norma passa a ter destinatários, vinculando-os através de um dever. Não cumprindo esse dever, os agentes terão de responder pelo incumprimento. E se, do lado do portador do valor tutelado pela norma, estiver, igualmente, um sujeito, este torna-se, para além de um bem ou valente, num titular de direitos.

A distinção entre esses três diferentes momentos normativos torna-se clara se atendermos à fórmula linguística dos mesmos. No primeiro caso, o da pura norma, temos algo como "Deve respeitar-se $x$ ", sem especificação de circunstâncias e de destinatários. No segundo caso, o da aplicação da norma a certas situações, temos algo como "Na circunstância $c$, deve respeitar-se $x$ ", especificando-se em que situações deve dar-se o referido respeito. No terceiro caso, o da aplicação da norma a sujeitos, temos algo como "O agente $a$, na circunstância $c$, deve respeitar $x$ ", especificando-se, para além da circunstância relevante, o destinatário da norma.

Agora, Hartmann já não acerta quando considera que é uma situação de não verificação do exigido pela norma a condição de aplicação da mesma. Isto, porque a razão de ser subjacente à regulação concreta da realidade pela norma só pode ser a de evitar a verificação de estados de coisas tidos por indevidos; a finalidade da aplicação da norma tem carácter preventivo. Deste modo, a 
haver condições de aplicação da norma, elas terão de expressar a possibilidade (tanto objetiva como subjetiva) conjunta de o conteúdo da norma vir a efetivar-se e de não se vir a efetivar num fato.

E, claro, para dizer tudo isto não necessitava Hartmann de falar em realização de valores nem de reduzir os valores à idealidade (objetiva). Em vez de passagem da esfera ideal para a esfera real, bastaria ao autor ter falado em abertura dos valores e comunicação da sua validade ao mundo; bastaria ter visto que essa dita esfera ideal é, afinal, a esfera de validade própria dos valores e que a referida realização é, afinal, o contato dessa validade com a realidade.

\section{Conclusão}

Hartmann, que com Scheler procurou uma alternativa satisfatória às propostas tradicionais de fundamento da normatividade, entre as quais se conta a teoria kantiana, é, ainda nos nossos dias, dos autores que com maior profundidade desenvolve a relação existente entre norma e valor. Se bem que a sua perspectiva não esteja isenta de problemas, não deixa de constituir uma frutuosa especulação, cheia de estimulantes intuições.

\footnotetext{
ABSTRACT

The clarification of the relation between norm and value was historically one of the main philosophical concerns of the phenomenological current of the movement known as Philosophy of Values. One of its major characters, Nicolai Hartmann, in his book Ethik, argues in favor of almost identifying one with the other. For him, the "ideal ought-to-be" (the one indifferent to the way reality is) already belongs to the nature of values, since they have an inherent tendency towards reality. In this communication, I'll criticize this thesis based on the meaning of the concepts involved.
} 